\title{
Design, Simulation and Experimental Investigation of Microstrip Patch Antennas and its Feed Line
}

\author{
Tarun Kumar Kanade \\ Research Scholar, \\ Department of Physics, \\ Govt. M. V. M., Bhopal
}

\author{
Alok Kumar Rastogi \\ Department of Physics and \\ Electronics \\ Institute for Excellence in Higher \\ Education, Bhopal
}

\author{
Sunil Mishra \\ Department of Physics and \\ Electronics \\ Institute for Excellence in Higher \\ Education, Bhopal
}

\begin{abstract}
This paper presents the modeling, simulations, fabrications and analysis of microstrip patch antenna $\&$ its feed lines. Microstrip antennas are of huge importance because of the advantages of their modest profile and less expensive printed circuit construction, and many forms have design and created for various applications. The characteristics parameters like dielectric constant $\left(\varepsilon_{r}\right)$, thickness of the substrate (h) and antenna's dominant-mode resonant frequency $\left(f_{r}\right)$ is transformed into the patch dimensions that is length (l) and width (w) of the microstrip patch. The rectangular microstrip patch antenna with modified feed lines are designed $\&$ simulated for wireless communication application that works at $2.4 \mathrm{GHz}$. The microstrip feed line for microstrip patch antenna plays an important role to determine the return loss, gain $\&$ its radiation pattern. By modifying the microstrip feed line or inserting some discontinuities in it the return loss of the patch antennas could be reduced considerably, while gain and radiation performance is improved. In this paper a microstrip patch antenna is designed and simulated on FR4 substrate, with different feed lines using software's based on MOM \& FEM techniques. The microstrip patch antennas were fabricated on FR4 substrate with different feed lines $S_{11}(\mathrm{~dB})$ were measured with Network analyzer. The work is of practical importance for microwave researchers and engineers.
\end{abstract}

Keywords-Microstrip patch antenna, return loss, feed line, finite element methods, method of moments and radiation loss.

\section{INTRODUCTION}

Wireless technologies have made a rapid progress in the recent years, and there has been considerable work done in the field of planar transmission lines or planar antennas. The $\mathrm{RF}$ or electronics devices like mobile phones, laptops, satellite communication, GPS, WLAN systems becomes compact, and the miniaturization of the patch antenna is the requirement of the compact device. Hence in design considerations, its results the reduction in antenna size for practical applications. The microstrip patch antenna has many advantages like compactness, light weight, low profile, inexpensive to fabricate and are conformable with planar or non-planar surfaces. In addition to above features the microstrip patch antenna is compatible with MICs and MMICs. The most significant disadvantages are that the antenna has a low gain narrow bandwidth, and is perceptive to fabrication errors. Microstrip is one of the most conventional and vital element in microwave communication systems for designing and fabricating MICs in the band 1-30 GHz. Microstrip transmission lines consists of two conductors one is a thin strip conductor of width $\mathrm{w}$ and thickness $t \&$ other side is completely metalized, between two conductors there is a substrate of dielectric constant $\left(\varepsilon_{\mathrm{r}}\right)$ and height (h) [1], [2]. The cross sectional view of a microstrip line is shown in Fig. 1. The physical and constructional view of a microsrip line is shown in Fig. 2. The electric and magnetic field lines in a microstrip transmission lines are shown in Fig. 3. Microstrip circuits comprise straight line and a variety of discontinuities like open circuits, gaps, bends, step changes in width, T-junctions and cross junctions [3], [4]. By introducing these discontinuities in a patch antenna its performance shall be altered or improved as per requirement. In a microstrip patch antenna the microstrip transmission line could be used as feed line. The proposed microstrip patch antennas are compact and find its application in the WLAN $802.11 \mathrm{~b}$ communication standard operating at $2.4 \mathrm{GHz}$. The simulations were carried out with introductory versions of SONNET software \& HFSS software which is based on MoM \& FEM respectively [5]-[8]. The cross sectional view of microstrip patch antenna is shown in Fig. 4. The constructional views of a microstrip patch antenna are shown in Fig. 5.

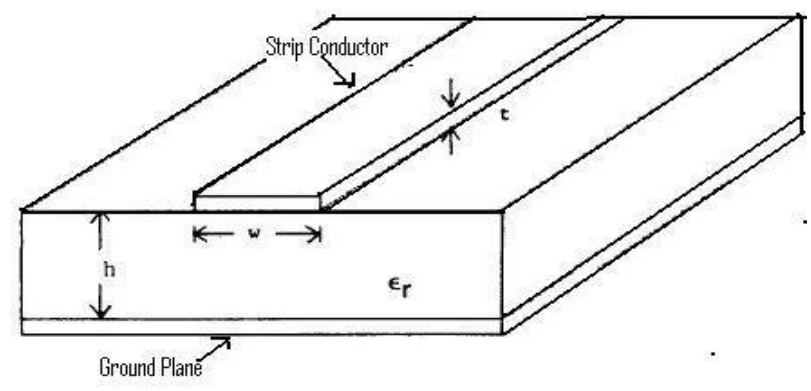

Fig. 1. Cross sectional view of Microstrip line

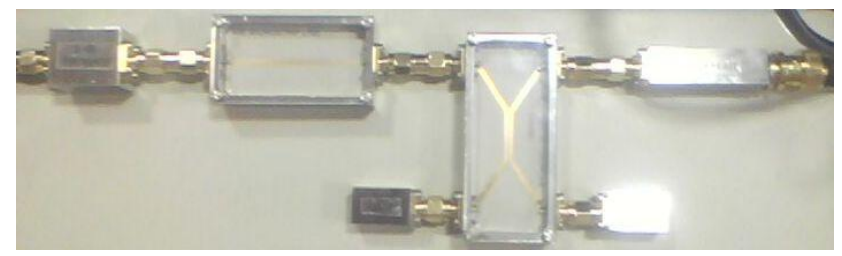

Fig. 2. Physical \& constructional view of Microstrip lines 


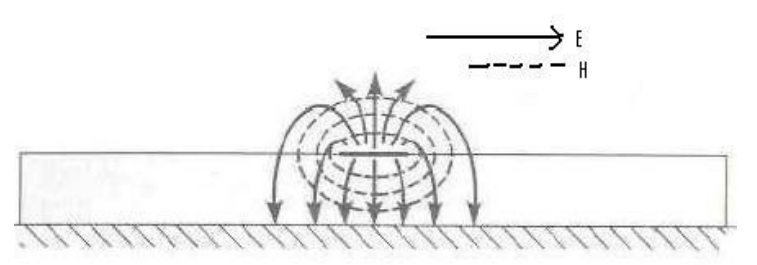

Fig. 3. Electric and magnetic fields at Microstrip transmission line

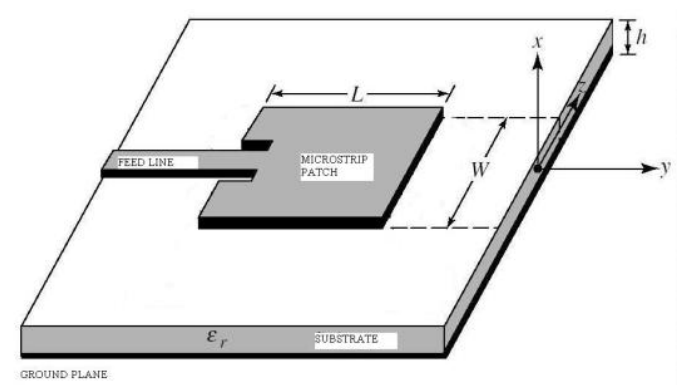

Fig. 4. Cross sectional view of Microstrip Patch Antenna

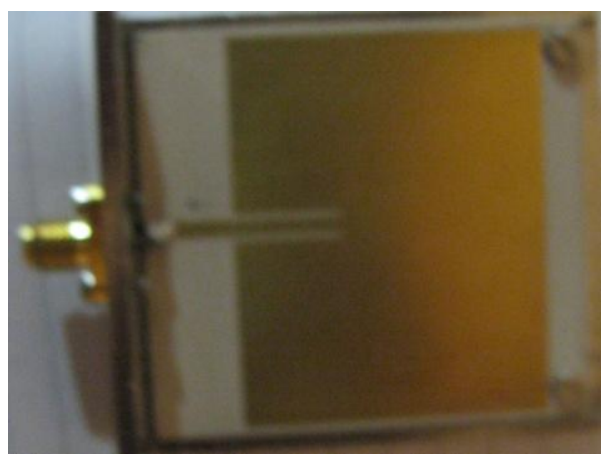

Fig. 5. Constructional view of Microstrip Patch Antenna

\section{MICROSTRIP PATCH ANTENNA DESIGN CONSIDERATIONS}

The procedure for design \& analysis of radiating microstrip patch antenna involves parameters like length (l) \& width (w) related to rectangular microstrip elements to realize the desired resonant frequency, input impedance, rectangular parameters and radiation pattern. A simplest geometry of microstrip line has been chosen to design feed line to provide small stray radiation from stripline. The microstrip feed line is a conducting strip to a large extent of smaller width as compared to the patch [5]. In this paper FR4 substrate with dielectric constant 4.4 is taken for the design of patch antenna. The patch antennas are design and simulated at a frequency 2.4 GHz with straight, single step discontinuities and double step discontinuities feed line separately. The dimensions (width and length) of the patch are finite along the length and width; the fields at the edges of the patch experience fringing. The total fringing field is a role of the dimensions of the patch i.e. width \& length and the height of the substrate [6], [7].

The practical design of rectangular microstrip patch antenna is based on the simplified formulation and the required inputs include dielectric constant of the substrate $\varepsilon_{\mathrm{r}}$, resonant frequency $\left(f_{r}\right)$ and the height of the substrate $(h)$ which provides the width $\&$ length of the patch and the feed line [8]-[10]. By using the design formulations microstrip patch antennas with straight, single step feed line, double step feed line and with inside feed is designed \& simulated and is shown in Fig. 6. The layout design methodology for the design \& simulation of mircostrip patch antenna is represented in flowchart of Fig. 7.

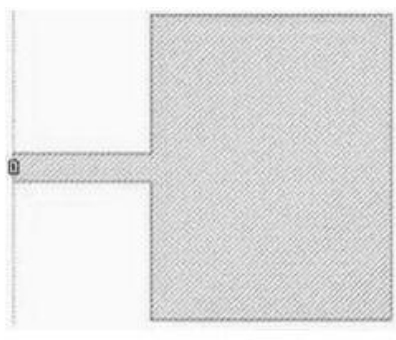

(a)

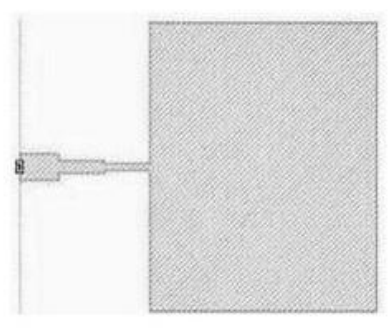

(c)

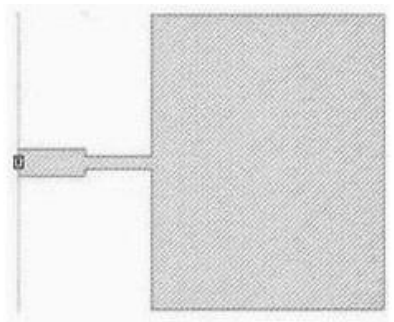

(b)

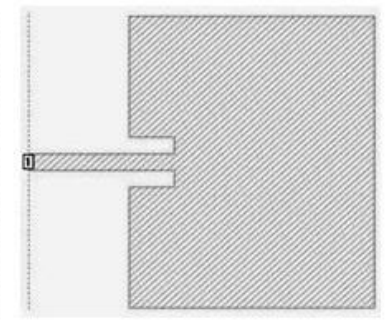

(d)
Fig. 6. Two D view of Microstrip Patch Antenna (a) Straight Feed Line (b) Single Step Feed Line (c) Double Step Feed Line (d) Inside Feed Line

\begin{tabular}{|c|}
\hline $\begin{array}{c}\text { Frequency of Operation }\left(\mathrm{f}_{0}\right) \\
\text { Dielectric Constant of the substrate }\left(\varepsilon_{\mathrm{r}}\right) \\
\text { Height of the dielectric substrate }(\mathrm{h})\end{array}$ \\
\hline Calculation of the Width $(\mathrm{w})$ \\
\hline Calculation of the effective dielectric constant \\
$\left(\varepsilon_{\text {eff }}\right)$
\end{tabular}

Fig. 7. Flowchart for finding parameters \& designing simulation model 


\section{ANALYSIS OF MICROSTRIP PATCH ANTENNA}

The microstrip patch antenna is designed, simulated and analyzed with initial versions of software's based on MoM and FEM. The microstrip patch antenna is designed on FR4 substrate $\left(\varepsilon_{\mathrm{r}}=4.4\right)$. The output parameters like return loss, radiation patterns, and current at the surface is better for patch antenna with double step feed line rather than a patch antenna with straight line. The compared return loss for FR4 substrate with dielectric constant $\varepsilon_{\mathrm{r}}=4.4$ using MoM \& FEM based software's are shown in Fig. 8 and Fig. 9. From figure it is clear that the microstrip patch antenna with double step feed line has better return loss as compared to straight feed line and single step feed line. In both FEM and MoM simulation and analysis of patch antenna the return loss for all three substrates is better for patch antenna with double step feed lines as compared to straight feed line.

The microstrip patch antennas were fabricated using FR4 substrate, since FR4 $\left(\varepsilon_{\mathrm{r}}=4.4\right)$ based PCBs are readily available and it is an affordable substrates. The fabricated microstrip patch antennas for three different feed lines i.e. straight feed line, single step feed line and double step feed line are shown in Fig. 10. The measured frequency response or S-parameters values i.e. return loss $\mathrm{S}_{11}(\mathrm{~dB})$ for three different patch antennas were measured using Rohde \& Schwarz, ZNB8, Vector Network Analyzer, $9 \mathrm{KHz} . .8 .5$ $\mathrm{GHz}$. The measured frequency response or return loss $\mathrm{S}_{11}(\mathrm{~dB})$ for straight feed line microstrip patch antenna at $2.223 \mathrm{GHz}$ is $-11.767 \mathrm{~dB}$ and is shown in Fig. 11. The measured frequency response $S_{11}(\mathrm{~dB})$ for single step feed line microstrip patch antenna at $2.26 \mathrm{GHz}$ is $-10.45 \mathrm{~dB}$ and is shown in Fig. 12.The measured frequency response or return loss $\mathrm{S}_{11}(\mathrm{~dB})$ for double step feed line microstrip patch antenna at $2.395 \mathrm{GHz}$ is $-19.96 \mathrm{~dB}$, its file view is shown in Fig. 13, and its screen view is shown in Fig. 14. The measured results obtained by double step feed line microstrip patch antenna is appropriate and it indicates that the step discontinuities in a feed line increases the performance of microstrip patch antenna.

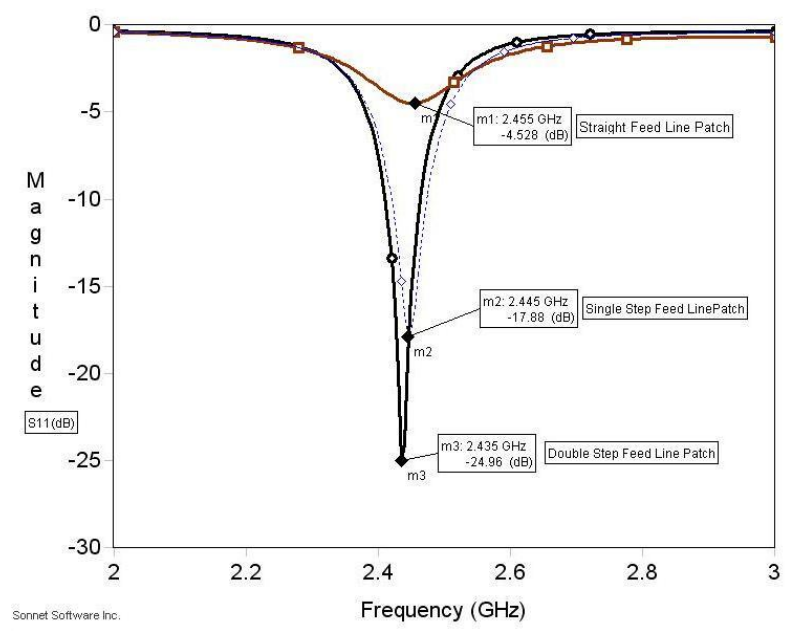

Fig. 8. Return loss $\mathrm{S}_{11}(\mathrm{~dB})$ versus frequency on FR4 $\left(\varepsilon_{\mathrm{r}}=4.4\right)$ using MoMs software.

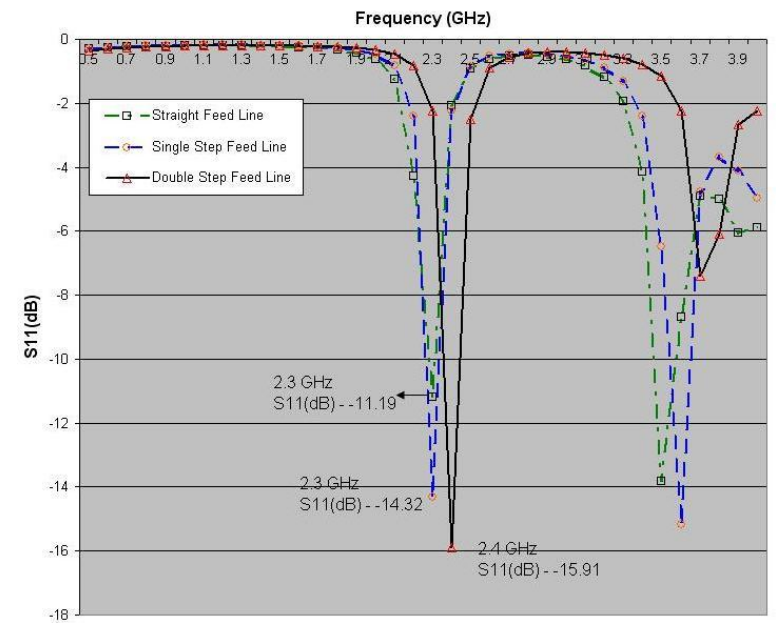

Fig. 9. Return loss $S_{11}(d B)$ versus frequency on FR4 $\left(\varepsilon_{\mathrm{r}}=4.4\right)$ using FEM software.

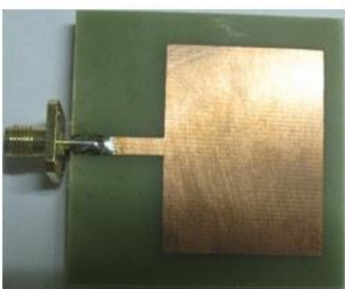

(a)

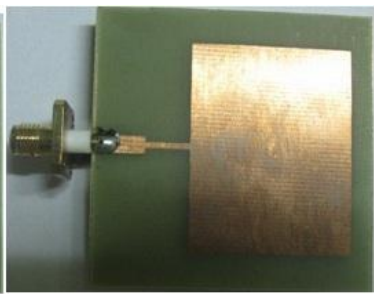

(b)

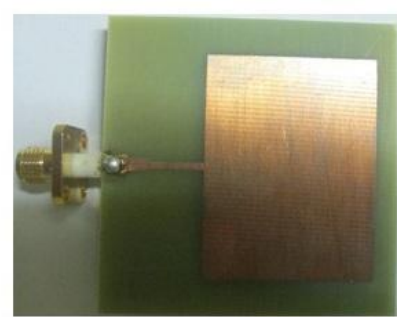

(c)

Fig. 10. Fabricated Microstrip Patch Antenna (a) Straight feed line (b) Single step feed line (c) Double step feed line

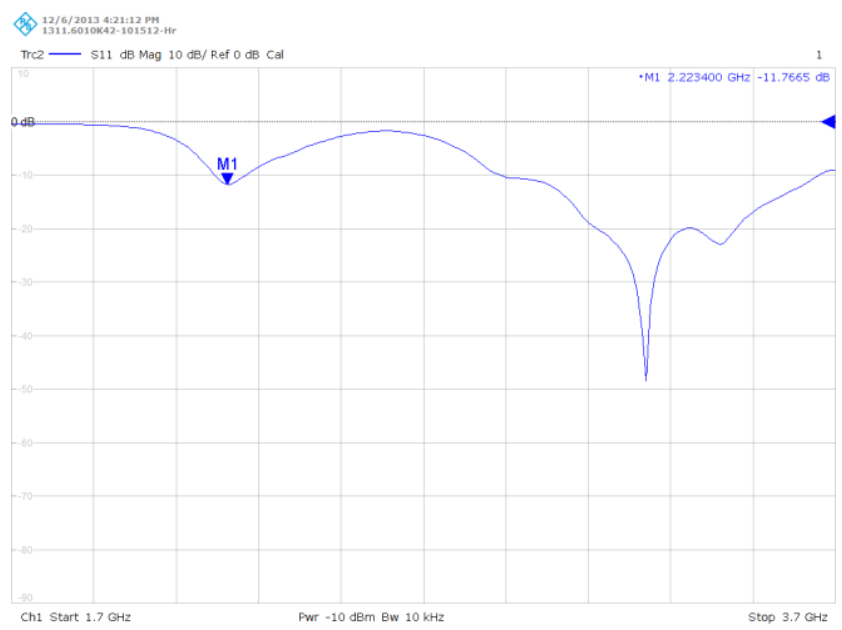

Fig. 11. Measured frequency response $S_{11}(d B)$ for straight feed line microstrip patch antenna on FR4 $\left(\varepsilon_{\mathrm{r}}=4.4\right)$ 


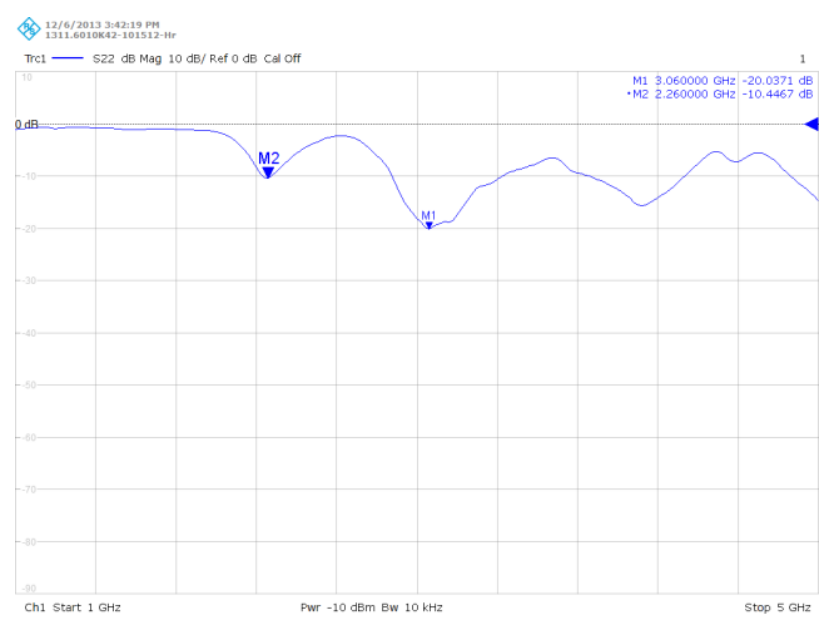

Fig. 12. Measured frequency response $\mathrm{S}_{11}(\mathrm{~dB})$ for single step feed line Microstrip Patch Antenna on FR4 $\left(\varepsilon_{\mathrm{r}}=4.4\right)$

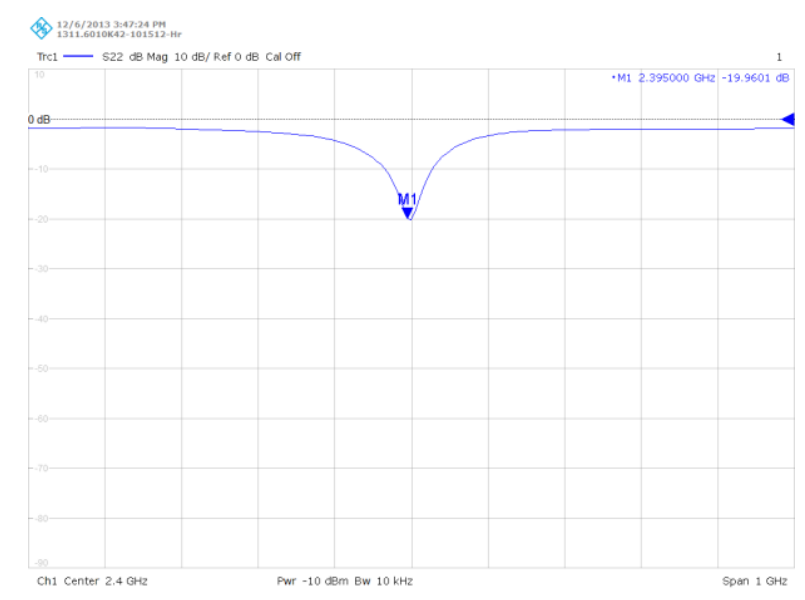

Fig. 13. Measured frequency response $\mathrm{S}_{11}(\mathrm{~dB})$ for double step feed line Microstrip Patch Antenna on FR4 $\left(\varepsilon_{\mathrm{r}}=4.4\right)$

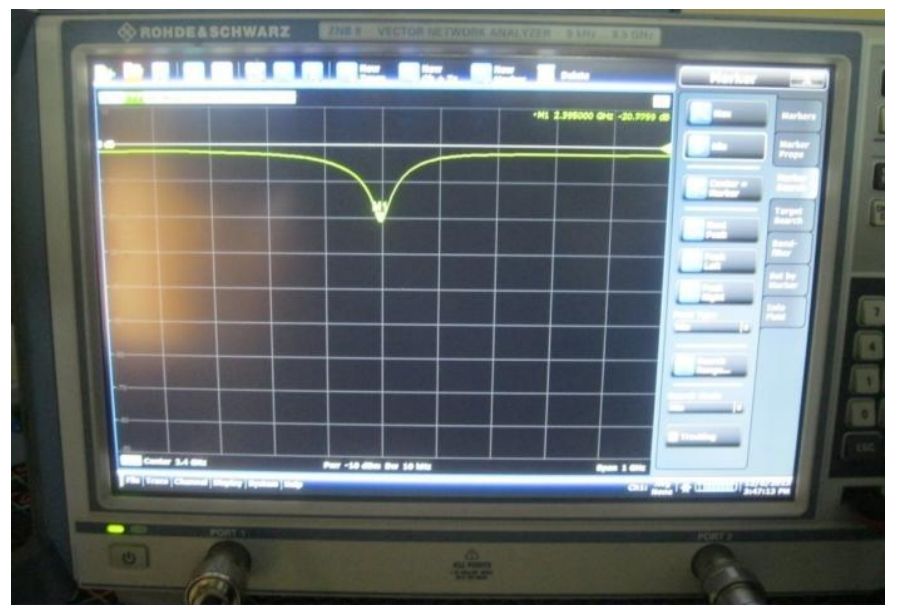

Fig. 14. Measured frequency response (screen View) $S_{11}(d B)$ for double step feed line Microstrip Patch Antenna on FR4 $\left(\varepsilon_{\mathrm{r}}=4.4\right)$

\section{CONCLUSIONS}

A low profile rectangular patch antenna and its feed lines is designed, analyzed and studied here at $2.4 \mathrm{GHz}$. The substrate used for designing antennas is FR4. The design \& simulation of microstrip patch antenna with various feed lines is proved to be successful on some level. The original goal of creating an antenna with step discontinuities in feed lines at $2.45 \mathrm{GHz}$ is to get a minimum return loss, optimum radiation pattern, gain and directivity. From the various analysis of microstrip patch antenna it is clear that a feed line is also responsible for optimum performance of patch antenna. The microstrip discontinuities especially step discontinuities i.e. single or double step makes an antenna performance better than a patch antenna with a straight feed line. The simulation and experimental results shown that a microstrip patch antenna with double step feed line has better results as compared with a straight line. The complementary research could be to take explanation of optimization of the position of the feed point.

\section{REFERENCES}

[1] Pozar, D. M., "Microstrip Antennas", IEEE procedngs, vol. 80, 79-91, January 1992.

[2] Garg, R., Bhartia, P., Bhal, I., and Ittipiboon, A., "Microstrip Antenna Design Handbook", Artech House Inc. Boston, 2001.

[3] Balanis, C. A, "Antenna Theory: amnalysis and Design", John Wiley \& sons, New York, 1997.

[4] Kumar, G. and K. P. Ray, "Broadband Microstrip Antennas", Artech House, 1981, 2003.

[5] Wong, Kin-Lu, "Compact and Broadband Microstrip Antennas", John Wiley \& sons, New York, 2002.

[6] Hoffman, R. K., "Handbook of Microwave Integrated Circuits", Norwood, MA: Artech House, 1987.

[7] Gupta K. C., Ramesh Garg, Inder Bahl and Prakash Bhartia, "Microstrip Lines and Slot Lines", Artech House Inc. Washington, 1996.

[8] Bharathi Bhat and Shiban K. Koul, "Stripline-like Transmission Lines for Microwave Integrated Circuits", Wiley Eastern Limited New-Delhi, 1980.

[9] Edwards, Terry, "Foundations for Microstrip Circuit Design", 2nd ed., Chichester, U.K: John Wiley \& Sons, 1992.

[10] Keith R. Carver and James W. Mink, "Microstrip Antenna Technology," IEEE Trans. Antenna Propagat., vol. AP-29, no.1, pp. 2-22, Jan. 1981.

[11] www.sonnetsoftware.com

[12] www.ansys.com.hfss 